\title{
Jet aircraft electric field due to its exhaust gases
}

\begin{abstract}
During flight, an aircraft acquires an electrostatic charge distribution on its skin due to various reasons, among which is the electrostatic polarity of the exhaust gases. Due to this electrostatic charge distribution, the aircraft, induces an electrostatic field at any point of its surrounding area. In this paper, a fast quantitative approach is proposed in order to compute the strength of this electrostatic field so as to determine if the break down electric field threshold for air ionization can be exceeded. If so, a stepped leader from an electrified cloud could be directed towards the aircraft, resulting in a lightning strike. This approach is based on the common mathematical background of potential flow and electrostatics. It was found that the strength of the electrostatic field induced by the aircraft is much less than the break down electric field threshold, therefore a lightning strike on the aircraft is unlike to occur.
\end{abstract}

Keywords: aircraft, exhaust, soot particles, electrostatic charging, electric field, panel
Volume 4 Issue 4 - 2020

Theodore I Lekas

Department of Aerodynamics and Flight Mechanics, Hellenic Air Force Academy, Greece

Correspondence: Theodore I Lekas, Department of Aerodynamics and Flight Mechanics, Hellenic Air Force Academy, Dekelia AFB,TGA I0I0, Dekelia, Attika, Greece, Email tleks@hotmail.com

Received: December 20, 2020 | Published: December 30, 2020

\section{List of symbols}

$\mathrm{U}=$ electrostatic potential $(\mathrm{V})$ (m)

$\mathrm{x}, \mathrm{y}, \mathrm{z}=$ coordinates of a target point in a panel frame of reference

$\mathrm{x}_{\mathrm{k}}, \mathrm{y}_{\mathrm{k}}, \mathrm{z}_{\mathrm{k}}=$ coordinates of panel corner point $\mathrm{k}$ in a panel frame of reference $(\mathrm{m})$

$\vec{n}, \vec{t}, \overrightarrow{1}=$ right orthogonal frame of reference at the centroid $G$ of each panel

$\overrightarrow{\mathrm{n}}=$ panel normal unit vector pointing outwards

$\overrightarrow{\mathrm{t}}, \overrightarrow{\mathrm{l}}=$ unit vectors tangent to the panel and such that $\overrightarrow{\mathrm{n}}, \overrightarrow{\mathrm{t}}, \overrightarrow{\mathrm{l}}$ be right orthogonal

$\overrightarrow{\mathrm{E}}_{\mathrm{R}}=$ resultant electric field vector at a given point $(\mathrm{V} / \mathrm{m})$

$\mathrm{q}=$ electrostatic charge strength distribution at the surface of each panel (Coulomb) per $\mathrm{m}^{2}$

\section{Introduction}

In flight, the skin of an aircraft is electrostatically charged, mainly due to thunder cloud proximity, friction with the surrounding airflow, impacts of atmospheric crystals ( $p$-static charging) and exhaust gas polarity. Thus, the aircraft induces an electrostatic field at any point of its surrounding area. In case of flight in a region where an ambient electrostatic field exists, as for instance in the vicinity of a thunder cloud, due to the resultant electrostatic charge distribution on the aircraft skin, an electrostatic field could created and ionizing the air so that a stepped leader might be attracted..$^{1-3}$ in particular, the electrostatic charging of the aircraft due to its exhaust gas polarity can also create a radio frequency interference according to. ${ }^{4}$

Engine exhaust gases contain a large amount of charged particles, called soot particles. Soot particles can be generated during the combustion or by flow disturbances in the gas path inside the propulsive system, for instance blade rubbing or abnormal combustion. ${ }^{5,6}$ Exhaust gases are slightly more ionized than the surrounding air, so it is unlikely that they can attract a step leader or create a lightning flash (in contrast to rocket exhaust plumes). By discharging electrostatic charges through its exhaust gases, a jet aircraft acquires an electrostatic charge distribution on its skin, of opposite sign.
The electric field induced by this electrostatic charging of the skin creates radio frequency interference which depends on aircraft configuration and engine type. This disturbance increases the ambient noise level of the equipment, making reception difficult. ${ }^{4}$ On the other hand, unlike the case of $\mathrm{p}$-static charging procedure, no corona discharge is noticed in fair weather conditions flight, ${ }^{7}$ which might indicate that the effects of the electrostatic charging of the aircraft due to engine exhaust gases polarity can be neglected. This is supported by the fact that entry points are, so far, never reported on the engine exhaust, except if the exhaust is located at the rear extremity of the aircraft. ${ }^{7}$

In order to have a quantitative insight of the problem, in this paper an approach for computing the electrostatic charges distribution acquired on the skin of an aircraft of arbitrary geometry due to the exhaust gases electrostatic polarity, is presented. It is based on measured electrostatic potential acquired by an aircraft due to jet engines exhaust gases. ${ }^{8}$ This approach uses singularities and is based on the fact that electrostatics and potential flow theory have the same mathematical background.

The resultant electric field induced by the electrostatic charges acquired by the aircraft at points of the surrounding area nearby extremities like wing, horizontal stabilizer and vertical fin tips, as well as nearby the nose and the rear cone extremity will then be calculated. The above locations are chosen because of their relatively small curvature radius. These values will be compared to the corresponding breaking down electric field value of air, which equals to 300.000 $\mathrm{V} / \mathrm{m}$.

\section{Presentation of the approach}

The external surface of an aircraft of arbitrary geometry is described by a number of points, which are combined by three or four so as to form plane panels. The coordinates of these points are expressed in a global frame. The origin $\mathrm{O}$ of this frame is located at the nose of the aircraft, the $\vec{X}$ axis is parallel to the longitudinal axis of the aircraft and directed towards the tail, the $\overrightarrow{\mathrm{Y}}$ axis is parallel to the span and directed towards the right wing tip (pilot's point of view) and the $\vec{Z}$ axis is such that the frame $\mathrm{O} \overrightarrow{\mathrm{X}} \overrightarrow{\mathrm{Z}} \mathrm{Z}$ is a right orthogonal one.

The dimensions of each panel are sufficiently small, while the number of panels is sufficiently large so as to avoid gaps and to 
describe as closely as possible the aircraft's geometry. It must be pointed out that there are a threshold number of panels, depending on the geometry of the aircraft, above which numerical problems usually occur. Each panel carries a homogeneous electrostatic charge distribution q, which has to be calculated. The electrostatic charge of the metallic parts of the aircraft skin induces an electric field at any point of the surrounding area.

According to,${ }^{8}$ the electrostatic potential $\mathrm{U}$ acquired by an aircraft due to its exhaust gases polarity can reach a value of $-10^{5}$ Volts. Due to the common mathematical background of electrostatics and potential flow theory, the aerodynamic potential of a source/sink distribution on a panel ${ }^{9}$ can also be used for electrostatic calculation purposes. All panels of the aircraft skin are at the same electrostatic potential $\mathrm{U}$. The electrostatic potential $\mathrm{U}$ of each panel is expressed in a panel right orthogonal frame (local frame $G, \vec{n}, \vec{t}, \overrightarrow{1}, G$ being the centroid of the panel). Since all corner coordinates are expressed in the global frame (or initial frame), a transfer from the global to the local frame and vice versa, is needed.

For electrostatic purposes, the flow potential equation is adequately modified. The electrostatic potential $U$ induced by each panel at a given point located at a position $\mathrm{x}, \mathrm{y}, \mathrm{z}$ in panel coordinates is given by equation (1):

$$
\mathrm{U}=\frac{\mathrm{q}}{4 \pi \varepsilon_{0}} \sum_{\mathrm{K}=1}^{\mathrm{N} 1}\left\{\left(\frac{\left(\mathrm{x}-\mathrm{x}_{\mathrm{K}}\right)\left(\mathrm{y}_{\mathrm{K}+1}-\mathrm{y}_{\mathrm{K}}\right)-\left(\mathrm{y}-\mathrm{y}_{\mathrm{K}}\right)\left(\mathrm{x}_{\mathrm{K}+1}-\mathrm{x}\right)}{\mathrm{d}_{\mathrm{K} \mathrm{K}+1}}\right) \ln \left(\frac{\mathrm{r}_{\mathrm{K}}+\mathrm{r}_{\mathrm{K}+1}+\mathrm{d}_{\mathrm{K} \mathrm{K}+1}}{\mathrm{r}_{\mathrm{K}}+\mathrm{r}_{\mathrm{K}+1}-\mathrm{d}_{\mathrm{K} \mathrm{K}+1}}\right)+|\mathrm{z}|\left(\tan ^{-1}\left(\frac{\mathrm{m}_{\mathrm{K} \mathrm{K}+1^{\mathrm{e}} \mathrm{K}_{\mathrm{K}}}}{\mathrm{zr}_{\mathrm{K}}}\right)-\tan ^{-1}\left(\frac{\mathrm{m}_{\mathrm{K} \mathrm{K}+1} \mathrm{e}_{\mathrm{K}+\mathrm{h}_{\mathrm{K}+1}}}{\mathrm{zr}_{\mathrm{K}+1}}\right)\right)\right\}
$$

$$
\begin{gathered}
\mathrm{d}_{\mathrm{kk}+1}=\sqrt{\left(\mathrm{x}_{\mathrm{k}+1}-\mathrm{x}_{\mathrm{k}}\right)^{2}+\left(\mathrm{y}_{\mathrm{k}+1}-\mathrm{y}_{\mathrm{k}}\right)^{2}}, \\
\mathrm{~m}_{\mathrm{K} \mathrm{K}+1}=\frac{\mathrm{y}_{\mathrm{K}+1}-\mathrm{y}_{\mathrm{K}}}{\mathrm{x}_{\mathrm{K}+1}-\mathrm{x}_{\mathrm{K}}} \\
\mathrm{h}_{\mathrm{K}}=\left(\mathrm{x}-\mathrm{x}_{\mathrm{K}}\right)\left(\mathrm{y}-\mathrm{y}_{\mathrm{K}}\right) \\
\mathrm{h}_{\mathrm{K}}=\left(\mathrm{x}-\mathrm{x}_{\mathrm{K}}\right)\left(\mathrm{y}-\mathrm{y}_{\mathrm{K}}\right) \\
\mathrm{r}_{\mathrm{K}}=\sqrt{\left(\mathrm{x}-\mathrm{x}_{\mathrm{K}}\right)^{2}+\left(\mathrm{y}-\mathrm{y}_{\mathrm{K}}\right)^{2}+\mathrm{z}^{2}}
\end{gathered}
$$

where $\mathrm{q}$ is the electrostatic charge distribution $\left(\right.$ Coulomb $\left./ \mathrm{m}^{2}\right)$ of the panel, $\varepsilon_{0}$ is the electrical permittivity of the air $\left(8,8510^{-12} \mathrm{~F} / \mathrm{m}\right)$, $\mathrm{x}_{\mathrm{k}}, \mathrm{y}_{\mathrm{k}}, \mathrm{z}_{\mathrm{k}}$ are the coordinates of the panel corners and $\mathrm{x}, \mathrm{y}, \mathrm{z}$ the coordinates of the target point $(\mathrm{m})$, all expressed in a panel frame. $\mathrm{N}=$ 3 or 4 for a triangular or a four corner panel respectively.

The electrostatic potential induced by all panels $\mathrm{j}$ to the centroid of panel $\mathrm{i}$ (the target point in this case) is given by equation 2 :

$$
\sum_{\mathrm{J}=1}^{\mathrm{M}} \mathrm{v}_{\mathrm{ij}} \mathrm{q}_{\mathrm{j}}=\mathrm{U}
$$

where $v_{i j}$ is the potential induced on panel $i$ by a panel $j$ carrying an electrostatic charge distribution equal to $1 . \mathrm{q}_{\mathrm{j}}$ is the electrostatic charge distribution carried by panel $\mathrm{j}$, which has to be calculated. $\mathrm{M}$ is the total number of panels approximating the external surface of the aircraft.

By applying equation (2) at the centroid of all $\mathrm{M}$ panels describing the surface of the aircraft, an $\mathrm{M}$ by $\mathrm{M}$ system of linear algebraic equations is obtained. The right hand side of the system is equal to the potential of the skin of the aircraft, which is constant and has the same value at all panels since the skin is an equipotential surface. So, the value of the electrostatic potential acquired by the aircraft skin due its exhaust gases polarity is the boundary condition of the computation.

The resultant electric field $\overrightarrow{\mathrm{E}}_{\mathrm{R}}$ induced by the electrostatic charge of each panel at any given point around the aircraft is based on the fact that:

$$
\overrightarrow{\mathrm{E}}_{\mathrm{R}}=-\overrightarrow{\operatorname{grad}}\left(\sum_{\mathrm{i}=1}^{\mathrm{M}} \mathrm{U}_{\mathrm{i}}\right)
$$

where $U_{i}$ is the contribution of the $i^{\text {th }}$ panel on the resultant electric field. The components of $\overrightarrow{\mathrm{E}}$ induced by all panels at a given point, in panel coordinates, are $\mathrm{E}_{\mathrm{x}}, \mathrm{E}_{\mathrm{y}}$ and $\mathrm{E}_{\mathrm{z}}$.
In order to obtain the exact forms of $\mathrm{E}_{\mathrm{y}}, \mathrm{E}_{\mathrm{y}}$ and ${ }_{\overrightarrow{\mathrm{Y}} \overrightarrow{\mathrm{Y}} \overrightarrow{\mathrm{Z}}}$ a rather lengthy process of derivation is required. Since these forms are rather lengthy and complicated, for space saving reasons they are not presented here. It must be pointed out that, in order to obtain the resultant field due to all panels, the above components are to be transferred in the $\mathrm{O} \vec{X} \vec{Y} \vec{Z}$ frame of reference.

\section{Results and discussion}

Numerical generic airliner geometry of $50 \mathrm{~m}$ length and $60 \mathrm{~m}$ wingspan is created and shown in figure 1. Due to the symmetry of the aircraft about a plane perpendicular to the span, only its half is presented in Figure 1, but in the computation of the electrostatic charges the entire aircraft geometry is taken into account through symmetry projections. An in-house numerical code was used for the electric field calculation. The $\mathrm{M}$ by $\mathrm{M}$ linear algebraic equation system is solved based on a singular value decomposition numerical method. ${ }^{10}$ This approach can be applied to any aircraft geometry, propulsion system type and electrostatic potential value.

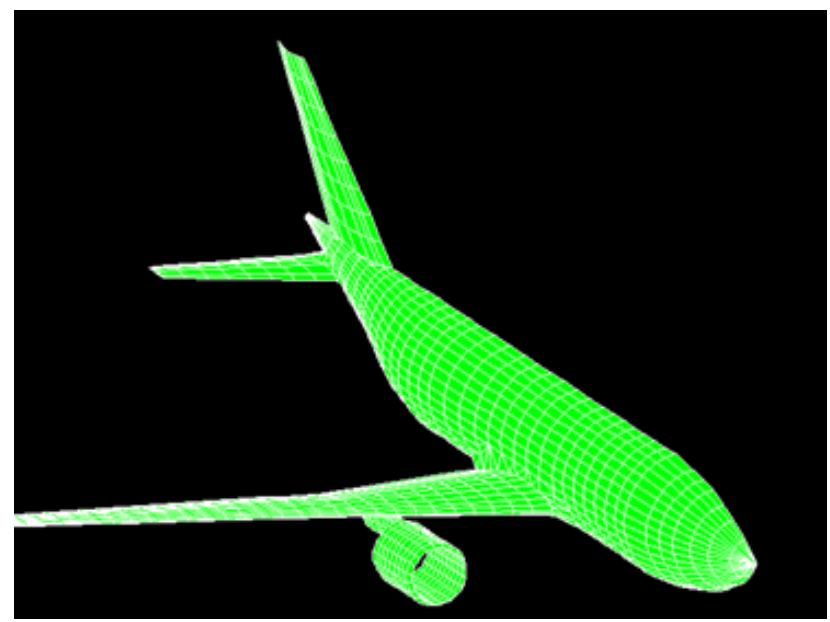

Figure I Generic airliner geometry.

Table 1 shows the strength of the induced electric field at the extremities of the aircraft for initial skin electrostatic potential values of $-10^{4},-10^{5}$ and $-10^{6} \mathrm{~V}$ respectively. In all cases, the points of interest are at a distance of $0.5 \mathrm{~m}$ from the aircraft. From table 1, it can be seen that the induced electric field strength is always less than 300.000 $\mathrm{V} / \mathrm{m}$, so no ionization of the air occurs. Whether radio frequency interference occurs or not, depends on the technical specifications of 
the corresponding equipment. But, it seems unlikely that a stepped leader can be attracted.

Table I Strength of the Induced electric field in $\mathrm{kV} / \mathrm{m}$ at the extremities of the aircraft for exhaust gases electrostatic potential values equal to $-10^{4},-10^{5}$ and $-10^{6}$ respectively

\begin{tabular}{llll}
\hline Ex. Gas Potential (V) & $-10^{4}$ & $-10^{5}$ & $-10^{6}$ \\
\hline Nose & 1,477 & 14,775 & $1,47,751$ \\
Rear cone & 1,106 & 11,054 & $1,10,540$ \\
Wing tip & 1,720 & 17,207 & $1,72,077$ \\
Hor. Stab.Tip & 0,751 & 7,513 & 75,134 \\
Vert. Stab.Tip & 0,339 & 3,398 & 33,982 \\
\hline
\end{tabular}

\section{Conclusion}

In this paper, a quantitative approach was presented to compute the electrostatic field strength induced due to the exhaust gases polarity of a jet aircraft. It was found that the strength of the induced electric field close to the wing, horizontal stabilizer and fin tips, as well as close to the nose and the rear cone is less than the corresponding value of the break down electric field of air. Consequently it is unlikely a stepped leader can be directed towards the aircraft due to the exhaust gas polarity. It also appears that there might not influence on the navigation and communication systems of the aircraft, of course according to their specifications.

\section{Acknowledgments}

None.

\section{Conflicts of interest}

Author declares that there is no conflict of interest.

\section{References}

1. Jones JJ. Electric Charge Acquired by Airplanes Penetrating Thunderstorms. Journal of Geophysical Research. 1990;95(10):1658916600 .

2. Uman MA, Rakov VA. The interaction of lightning with airborne vehicles. Progress in Aerospace Sciences. 2003;39(1):61-81.

3. Morgan D, Hardwick CJ, Haigh SJ, e al. The Interaction of Lightning with Aircraft and the Challenges of Lightning Testing. Aerospace Lab Journal. 2012;5:1-10.

4. O'Neil JF. Static electricity in flight threatens aircraft safety. JAYFON Enterprises: Aerospace Consultant; 1992. 21 p.

5. Sorokin A, Arnold F. Electrically charged small soot particles in the exhaust of an aircraft gas-turbine engine combustor: comparison of model and experiment. Atmospheric Environment. 2004;38(17):2611-2618.

6. Sorokin A, Arnold F. Organic positive ions in aircraft gas-turbine engine exhaust. Atmospheric Environment. 2006;40(32):6077-6087.

7. Fisher FA, Plurner JA. Lightning protection of aircrafts, NASA Reference Publication 1008; 1977.

8. Pierce ET. Perturbations produced by Jet Aircraft on the Earth's Electric Field. Journal of Applied Meteorology, Notes and Correspondence. 1964;3:805-806.

9. Katz J, Plotkin A. Low-Speed Aerodynamics: From Wing Theory to Panel Method. McGraw-Hill Inc; 1991. 351 p.

10. Press WH, Teukolsky AS, Vetterling WT, e al. Numerical Recipes in FORTRAN 77: The Art of Scientific Computing. 2nd ed. Vol 1, Press Syndicate of the University of Cambridge; 1992. 